\title{
Evaluation of Climate Change Impact on Streamflow (A Case Study of Dabus River,Abay Basin Ethiopia) Using CORDEX-RCP and SWAT Model
}

\author{
Bernabas Tesfaye \\ Hydraulic and Water Resources Engineering, Institute of technology, Bule Hora University, PO box 144, Bule \\ Hora, Ethiopia
}

\begin{abstract}
Climate change is becoming one of the most debating and threatening issues in terms of global context which alter regional hydrologic conditions and results in a variety of impacts on water resource systems. The aim of this study is to assess the impact of climate change on the stream flow of Dabus Sub-basin which located in upper Blue Nile Basin of Ethiopia. The CORDEX RCM downscaled and bias corrected were used for the climate projection. To estimate the level of impact of climate change, climate change scenarios of precipitation and temperature were divided into three time windows of 25 years as the whole from (2025-2099). Soil and water assessment Tool (SWAT) was calibrated and validated for stream flow simulation using SWAT-CUP with a method of SUFI2. The results showed that the value of calibration and validation reveals a good agreement with $\mathrm{R}^{2}=0.84$ during calibration and $\mathrm{R}^{2}=0.82$ during validation whereas $\mathrm{NSE}=0.75$ during calibration and $\mathrm{NSE}=0.72$ during validation. The maximum and minimum temperatures increase for the three time horizons under both scenarios with largest increase under RCP8.5. The largest increase of mean annual maximum temperature under RCP4.5 is $1.31^{\circ} \mathrm{C}$ while under RCP 8.5 that increase by $3.097^{\circ} \mathrm{C}$ in future periods of (2075-2099). Similarly, The largest increase of annual minimum temperature under RCP4.5 scenario by $1.28^{\circ} \mathrm{C}$ while $1.42^{\circ} \mathrm{C}$ under RCP 8.5 in future periods of (20752099). Compared to the base line period the total annual precipitation decrease for the three time horizons under both scenarios. A decrease of mean annual precipitation under RCP4.5 are $12.8 \%, 18.26 \%$ and $21.27 \%$ while under RCP8.5, it show decrease by $13.76 \%, 14.87 \%$ and $13.6 \%$ in the future periods of (2025-2049), (20502074)and (2075-2099) respectively. The stream flow projections are made in the future with two emission scenarios of RCP4.5 and RCP8.5, the study show that an average annual decrease in the stream flow up to $11.97 \%$ for RCP4.5 and up to $13.37 \%$ for RCP 8.5 in the next 75 years.
\end{abstract}

Keywords: Dabus Sub basin; SWAT; RCP Scenario; CORDEX RCM ; Climate Change

DOI: $10.7176 / \mathrm{CER} / 12-12-02$

Publication date: December $31^{\text {st }} 2020$

\section{Introduction}

Climate change refers to any systematic change in the long-term records of climate elements (such as temperature, pressure, or winds) sustained over various decades or longer time periods. Climate changes have had significant impacts on the natural systems. However its impact will be highly visible with the hydrological cycle. Ethiopia is heavily dependent on a rain-fed agriculture, and its geographical location and topography in combination with low adaptive capacity entail a high vulnerability to adverse impacts of climate change (Yirga, 2007). The country has been suffering from such disasters which manifest in the form of drought, flood, heavy rains, high temperature and frost with seemingly increasing trend from year to year (Abate, 2013; Tadege, 2007). Evaluating future precipitation and temperature change result in the study area show the fluctuation in extreme hydrological events that may happen in the future and helps to convey valuable information on the future projected climate change variables in Dabus Sub basin also to design a policy strategies to incorporating the appropriate adaptations and mitigation measures to preserve water resources in light of future climate change scenarios in the basin.

Therefore, projection of climate change impact on rivers of the country should not be neglected on the future development plan. Therefore, this study tried to investigate how changes in climate element might translate into changes in stream flow in the Dabus Sub basin in particular. Hence, the research focuses on using dynamically downscaled regional climate model at regional-scale with a Regional Climate Model Outputs, RCPs, archived in CORDEX-Africa project Domain and using SWAT model to forecast the stream flow change at Dabus Sub basin for the future climate variables such as Precipitation, Maximum Temperature and Minimum Temperature compared to the present condition.

\section{Materials and Methods}

\subsection{Description of the Study area}

The Dabus River is one of the major tributaries of the Blue Nile River. It starts south of the Benishangul Gumuz Nation Regoinal State in Begi woreda of Oromia National Regional State and flows towards north. The lower and middle parts of the Dabus sub-basin fall in the BGNRS. The sub basin has an area of 21,030 $\mathrm{km}^{2}$. The Dabus sub 
basin lies between $8^{\circ} 52^{\prime}$ and $10^{\circ} 45^{\prime} \mathrm{N}$ and $34^{\circ} 29^{\prime} 15^{\prime \prime}$ and $35^{\circ} 38^{\circ} \mathrm{E}$. The sub-basin is characterized by contrasting differences in climatic condition, soil, and human activities across the traditional altitude zones (IPS, 2012b; BoFED, 2007).

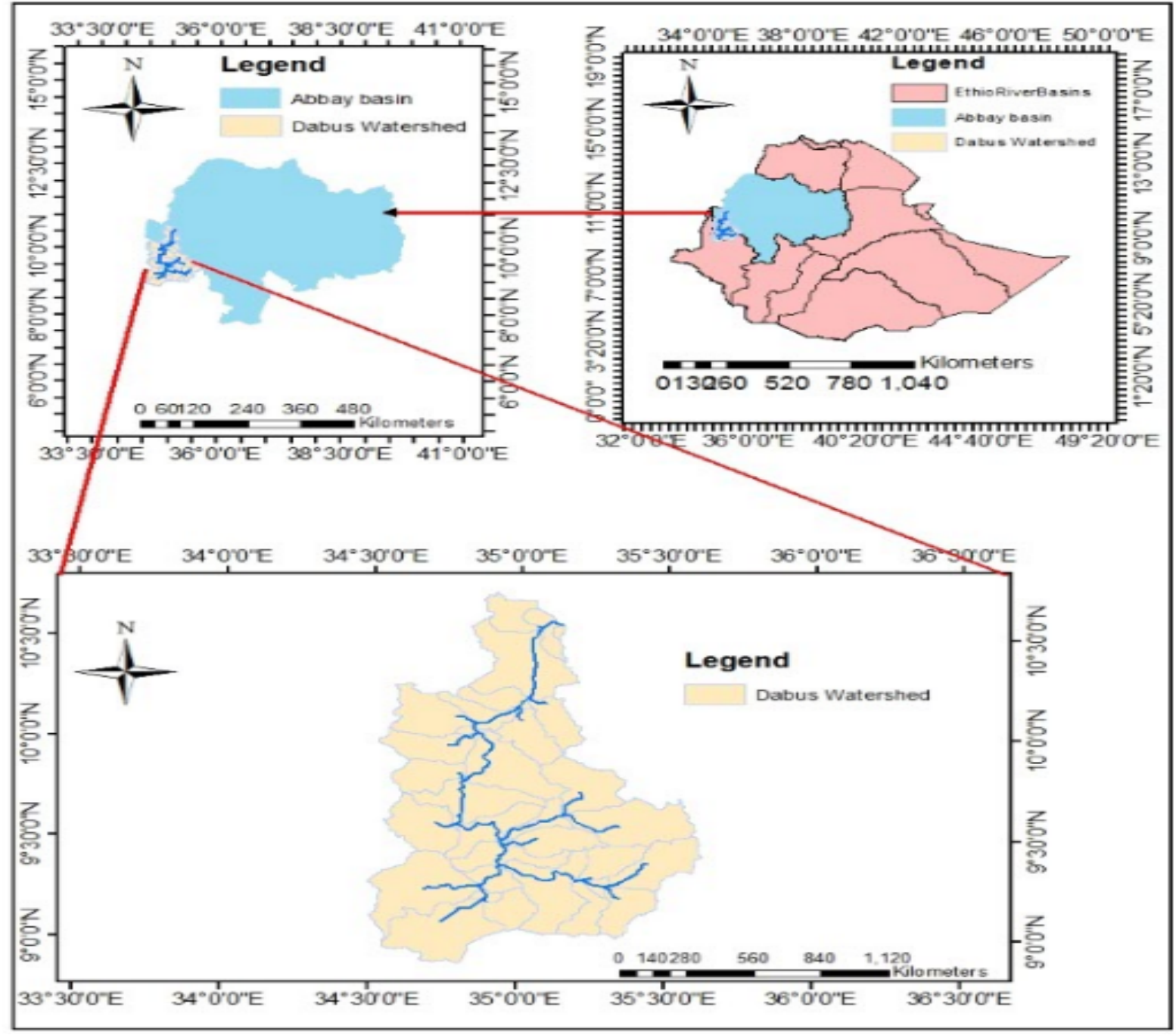

Figure. 2.1. Location Map of study area

\subsection{Climate change scenarios}

For assessing of future hydrologic regime in the Dabus sub-basin the following steps are followed. Data quality checking through homogeneity and consistency test and filling of missing data has been conducted. Using this filled data hydrologic model (Arc-swat hydrological) is calibrated and validated.

The new scenarios called Representative Concentration Pathways were developed and used for preparing fifth assessment report (AR5) of IPCC released in 2015 was used for this study.

Among the four RCP scenarios used in CMIP5 lead to radiative forcing values, RCP4.5 (stabilization scenario) declines in energy consumption and RCP8.5 (high emission scenario) representative of high emission scenarios are selected for the study.

The extracted daily RCMs of RCP4.5 and RCP8.5 output from grid cells covering the Dabus River sub basin are downscaled by finding the value at the observed meteorological stations from the nearest grid points. Bias corrections were carried out for RCMs output to the nearby observed stations on the watershed, then the future changes in maximum and minimum temperature and precipitation were assessed in the basin depend on the difference of bias corrected maximum and minimum temperature and precipitation from the observed maximum and minimum temperature and precipitation. The outputs of the future simulation of changes in maximum and minimum temperature and precipitation at three future time horizons those from (2025-2049), (2050 -2074) and (2075-2099) are ensembled and analyzed. For bias correction of the climate data, Linear scaling method (LS) aims to well match the monthly average of corrected values with observed ones than the other correction method. The correction method used in the study was the linear scaling method (LS), as the method aims to perfectly match the monthly average of corrected values with observed ones. The monthly corrected values are built depend on the 
differences between observed and raw RCP data. First the correction for climate data was made for historical period with that of the Observed data for the period of (1993-2017) then the correction factor is well applied for future time under each climate scenarios.

\section{Hydrological Modeling}

Third, the bias corrected RCM outputs of prepared maximum and minimum temperature and precipitation for the three window periods is used in SWAT hydrologic model in order to understand the hydrologic behavior of the basin for the scenario periods by simulating the stream flow for the three future window periods for the two emission scenario projections. Depend on the result the adaptation measure was proposed. The bias correction of climate outputs were done using linear scaling multiplicative method for precipitations and linear scaling additive for temperature, by comparing the observed precipitation and temperature at each station with the overlapping grid points of the RCM. For the hydrological analysis, the model is set to run for 25 years specified periods of three future time horizons as a scenario period under the two emission scenario projections of the selected RCMs.

\section{SWAT Model inputs}

The GIS input data (spatially distributed data) needed for the ArcSWAT interface include the Digital Elevation Model (DEM), land use, soil data and stream network layers. Weather data and observed stream flow will also use for prediction of stream flow and calibration purposes.

Spatial data in this study sets were projected to UTM 37 North and D_WGS_1984 datum. ArcGIS 10.2's raster and vector standard world re-project were used tools. Arc SWAT need all data to be in the same projection before any GIS processing can take place.

\section{SWAT Model Setup For The Study Area}

The SWAT model was set up using the data prepared described in above section and the (ARCSWAT, 2012) interface. The interface helped to create the stream network, delineate the catchment boundary from the DEM and further subdivide the catchment into sub-basins. The land cover and soil layers were used to generate HRUs. The climatic data was also integrated spatially to assign these data as the main drivers of the model. The general step followed to set up the model is described below:-

The first step was to load the Digital Elevation Model in the ARCSWAT version-2012 interface. The stream network was generated by use of a threshold area that defines the origin of a stream. The smaller the number, the more detailed the stream network generated by the interface. The locations of the river gauging location for watershed delineation were added manually as sub-basin outlets this was to ensure that the model calibration was done at the exact location. Once the entire watershed outlet is selected, the sub-basins are delineated and their parameters are calculated. Next, the landuse and soil maps are loaded. The lookup table for each map is also loaded in order for the interface to know which codes or names to assign to the different categories. Than slope classification is done by assigning a multiple slope option. Once the land use, soil map and slope have been loaded and reclassified, an overlay is done, resulting in landuse, soil and slope distribution within the sub-basins. The HRUs were then created by applying Dominant landuse, soil and slope. Then, the climate data defined in the user weather generator for metrological stations is loaded. At the final step, the SWAT input files are built and the model is set to run. 


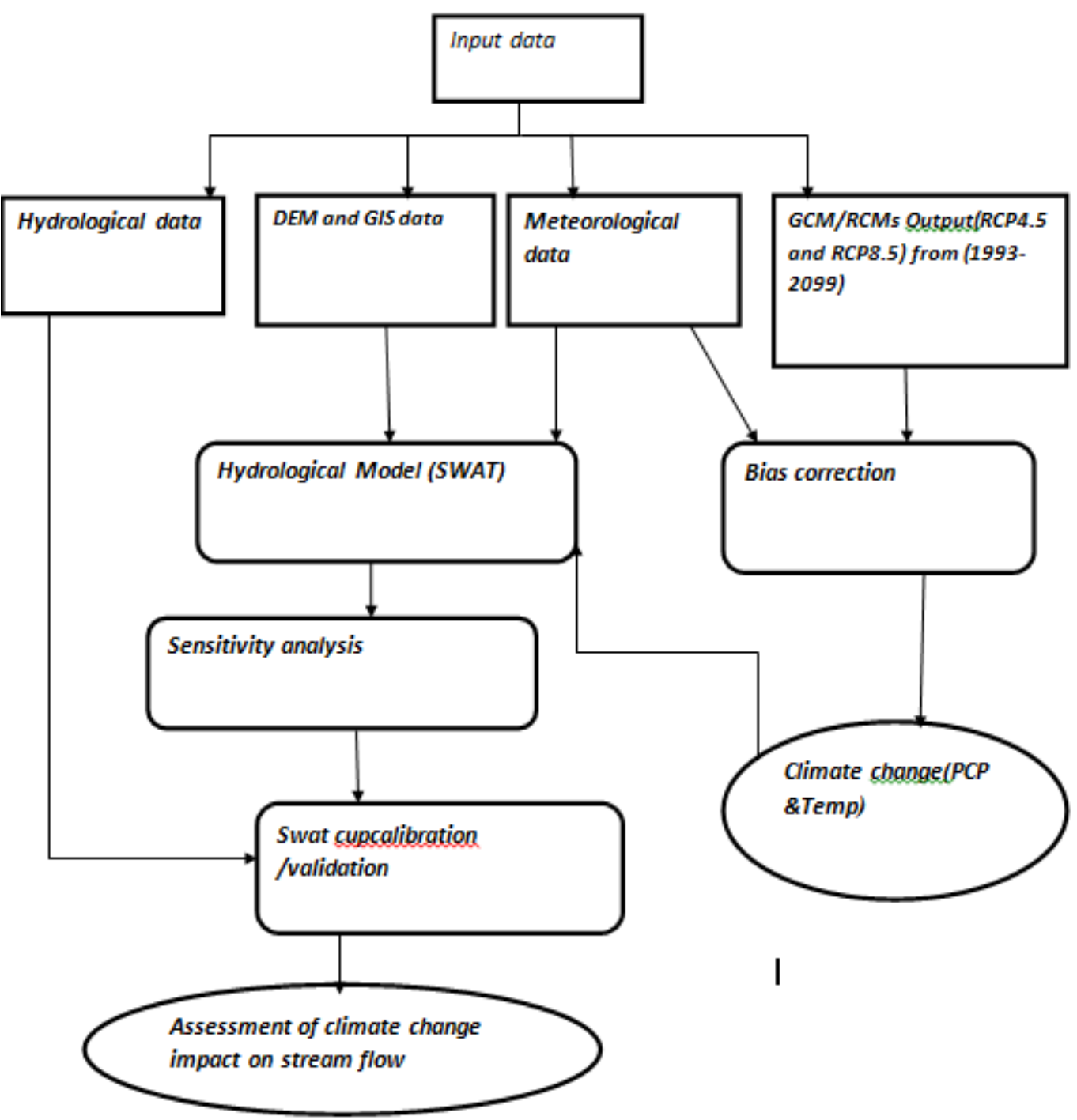

Figure 2.2. General methodology flow chart used in the study.

\section{RESULTS AND DISCUSSION}

\subsection{Future Climate projection}

\subsubsection{Monthly, seasonal and annual maximum and minimum temperature Changes}

The projected changes of bias corrected monthly, seasonal, annual maximum and minimum temperature over the entire Dabus River catchment during the three future periods of (2025-2049) and (2050-2074) and (2075-2099) are presented in Figure 3.1. There exist slightly increase in maximum and minimum temperature all along the year in all future periods, with largest increase in maximum temperature under RCP8.5 as $\left(+3.097^{\circ} \mathrm{C}\right)$ in the periods of (2075-2099). Also for RCP4.5 there exists slightly increase all over the periods with largest increase in maximum temperature as $\left(+1.91^{\circ} \mathrm{C}\right)$ in the periods of $(2075-2099)$. The largest increase in mean annual minimum temperature under RCP4.5 is $\left(+1.26^{\circ} \mathrm{C}\right)$ in the periods of $(2075-2099)$ and for RCP8.5 $\left(+1.71^{\circ} \mathrm{C}\right)$ in the periods of $(2075-2099)$. From the seasonal distribution of the RCMs simulated temperature for the three specified future periods as in Figure below show that all RCMs results were increase in the mean seasonal maximum and minimum temperature with respect to the baseline period. The increase in maximum and minimum temperature is indicated under RCP4.5 and RCP8.5 scenarios. But the magnitude varies between RCPs. All show increasing with the largest increase under RCP8.5. 


\section{RCP4.5}
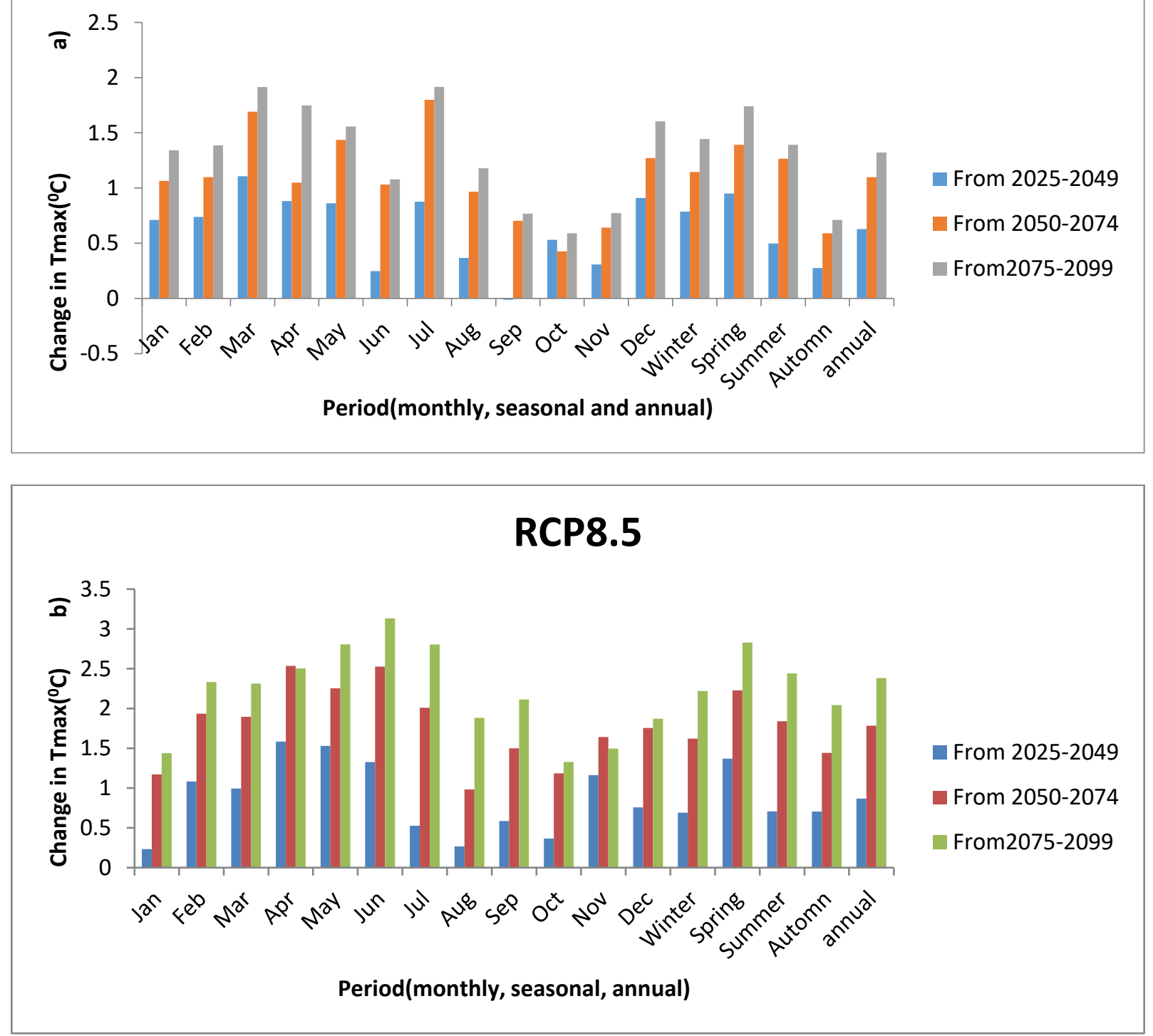

Figure 3.1: Monthly mean maximum temperature changes $\left({ }^{\circ} \mathrm{C}\right)$ (a) under RCP4.5 and (b) under RCP8.5 for the three future periods. 


\section{RCP4.5}
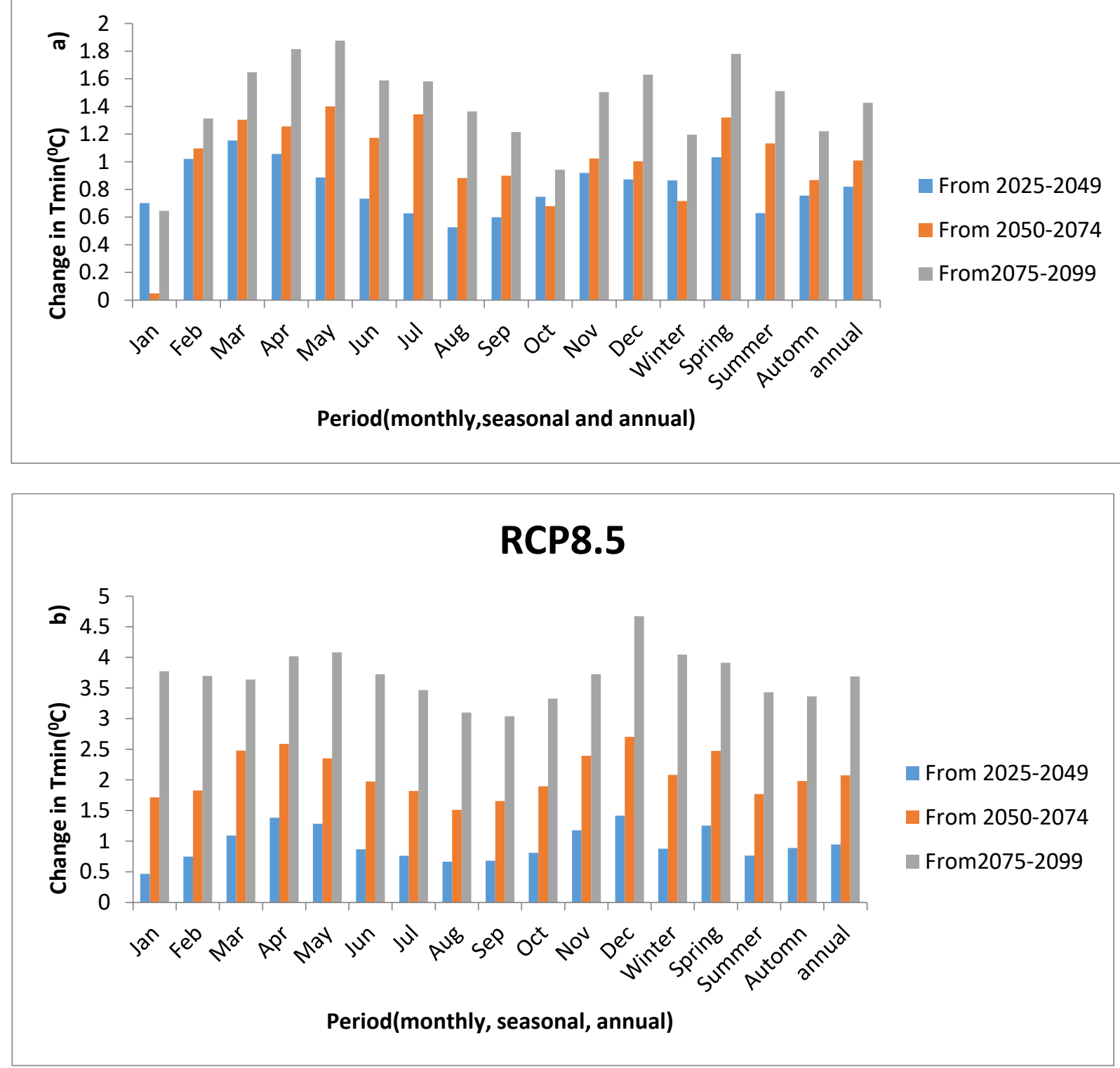

Figure 3.2: Monthly mean Minimum temperature changes $\left({ }^{\circ} \mathrm{C}\right)$ (a) under RCP4.5 and (b) under RCP8.5 for the three future periods.

\subsubsection{Monthly, seasonal and annual Precipitation Changes}

The changes of bias corrected mean monthly, seasonal and annual precipitation from the baseline over the entire Dabus River catchment during the future periods are presented in Figure 3.3, for both RCP4.5 and RCP8.5 scenarios. Precipitation increase in the Winter month of January during the period from (2050-2074) under RCP4.5 scenario. Compared to other months of seasons the distribution of precipitation seems mostly increasing during winter period of the year but decreases in the other left months of the season. Except small increase for the Spring season months under RCP4.5. In other cases, there exists decreases in monthly mean precipitation with the largest decrease for March (70.3\%) during the period from (2075-2099) under RCP4.5. Again for RCP8.5 the largest increase exist as (56.4\% ) for January from (2050-2074) and the highest decrease exist in October as(45.15\%) for the period of (2075-2099). Among the two RCPs the largest decrease in mean annual precipitation was under RCP 4.5 scenario in the period from 2075-2099 (21.27\%) whereas, under RCP 8.5 the largest decrease in mean annual precipitation (19.87\%) in the period of (2050-2074). On another side, the smallest decrease in mean annual precipitation was under RCP $4.5(12.79 \%)$ whereas under RCP 8.5, the smallest decrease in mean annual precipitation $(18.2 \%)$ in the period of $(2075-2099)$. 


\section{RCP4.5}

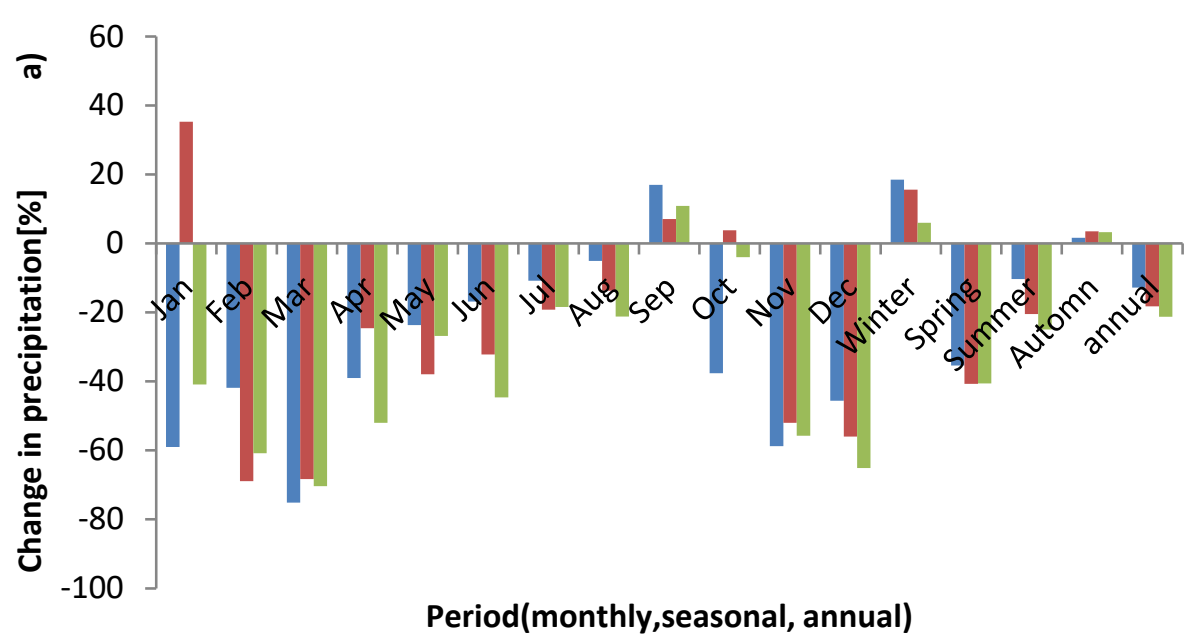

Period(monthly,seasonal, annual)

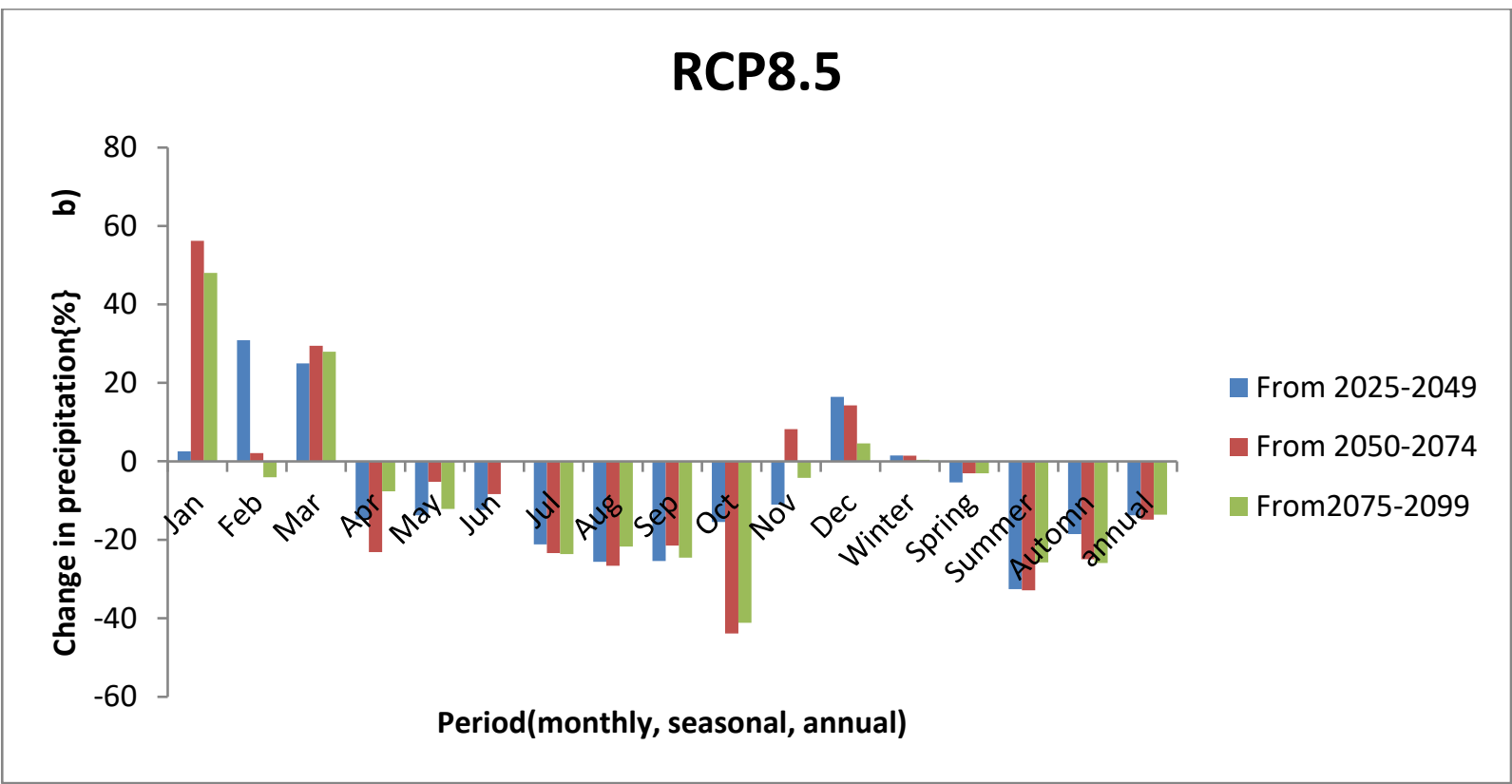

Figure 3.2: Monthly mean precipitation (a) under RCP4.5 and (b) under RCP8.5 for the three future periods. 


\subsection{Model Calibration and Validation}

The calibration statistics of the simulated flow indicates that $\mathrm{R}^{2}$ and NSE value were found as 0.84 and 0.75 whereas PBIAS and RSR were 11.9 and 0.60 respectively for monthly simulations in the calibration period. The General performance ratings for recommended statistics for a monthly time step as suggested by (Moriasi et al, 2007 ) indicate $\mathrm{R}^{2}>0.6, \mathrm{NS}>0.5$, PBIAS $< \pm 25$ and $\mathrm{RSR} \leq 0.7$, Based on the recommendations, the present result shows acceptable performance. However, the values need to be further validated in order to take as final calibration value. Figure 3.4 and 3.5 shows results of Monthly Calibration for gauged Aleltu near Nedjo.

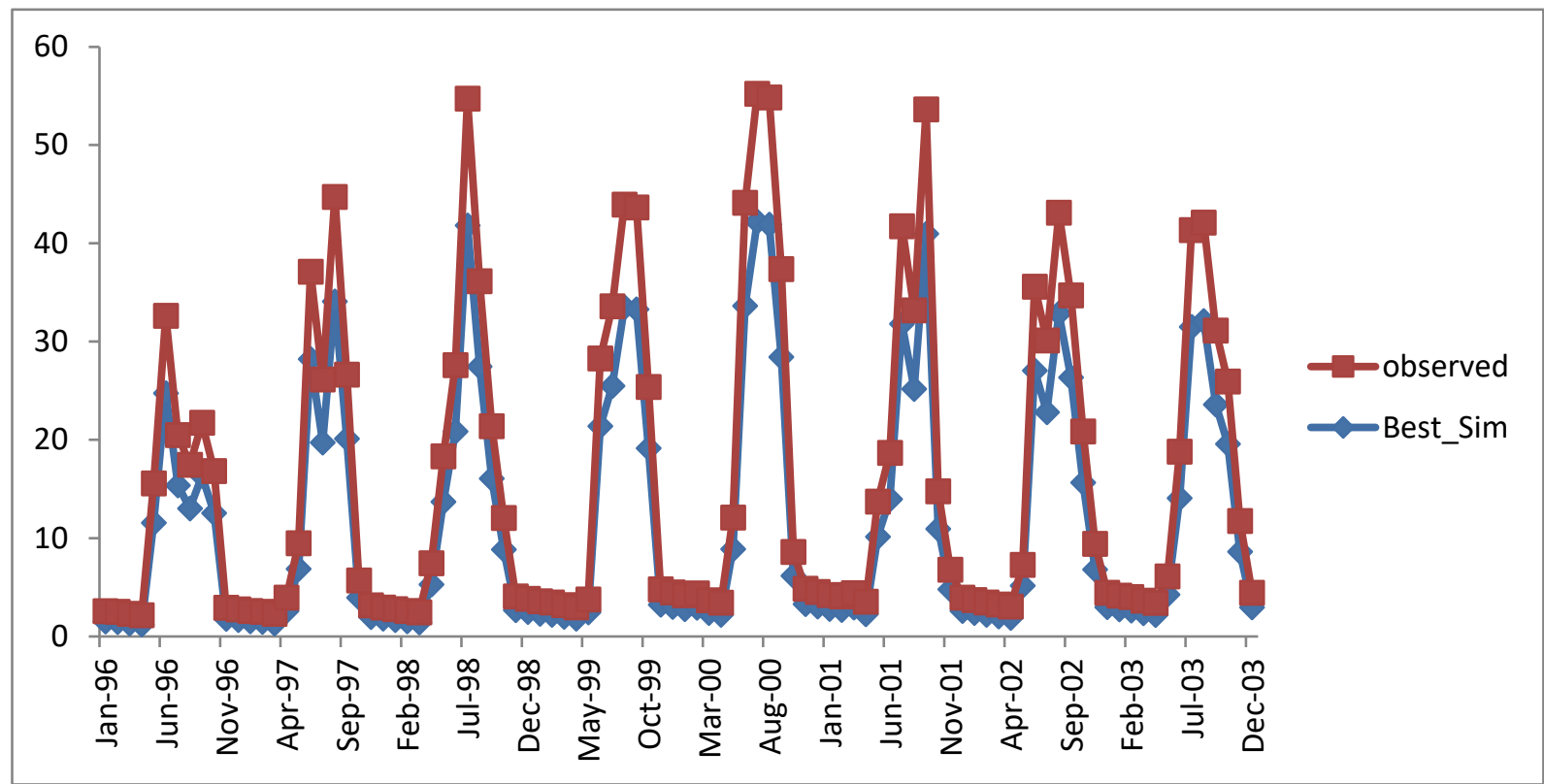

Figure 3.4. Calibration result of average monthly simulated and measured flow at Aleltu near Nedjo gauging station is located.

The validation was performed for six years period from January 1st, 2004 to December 31st, 2009. The validation statistics of the simulated flow indicates that $R^{2}$ and NSE value were found as 0.82 and 0.72 whereas PBIAS and RSR were -18.7 and 0.65 respectively for monthly simulations in the validation period this shows a good agreement between predicted stream flow and measured value. The calibration and validation result show that SWAT could successfully simulate reasonable monthly stream flow in Dabus basin sub basin. Figure 3.5 shows Validation of the model parameter for gauged Catchment from (2004-2009).

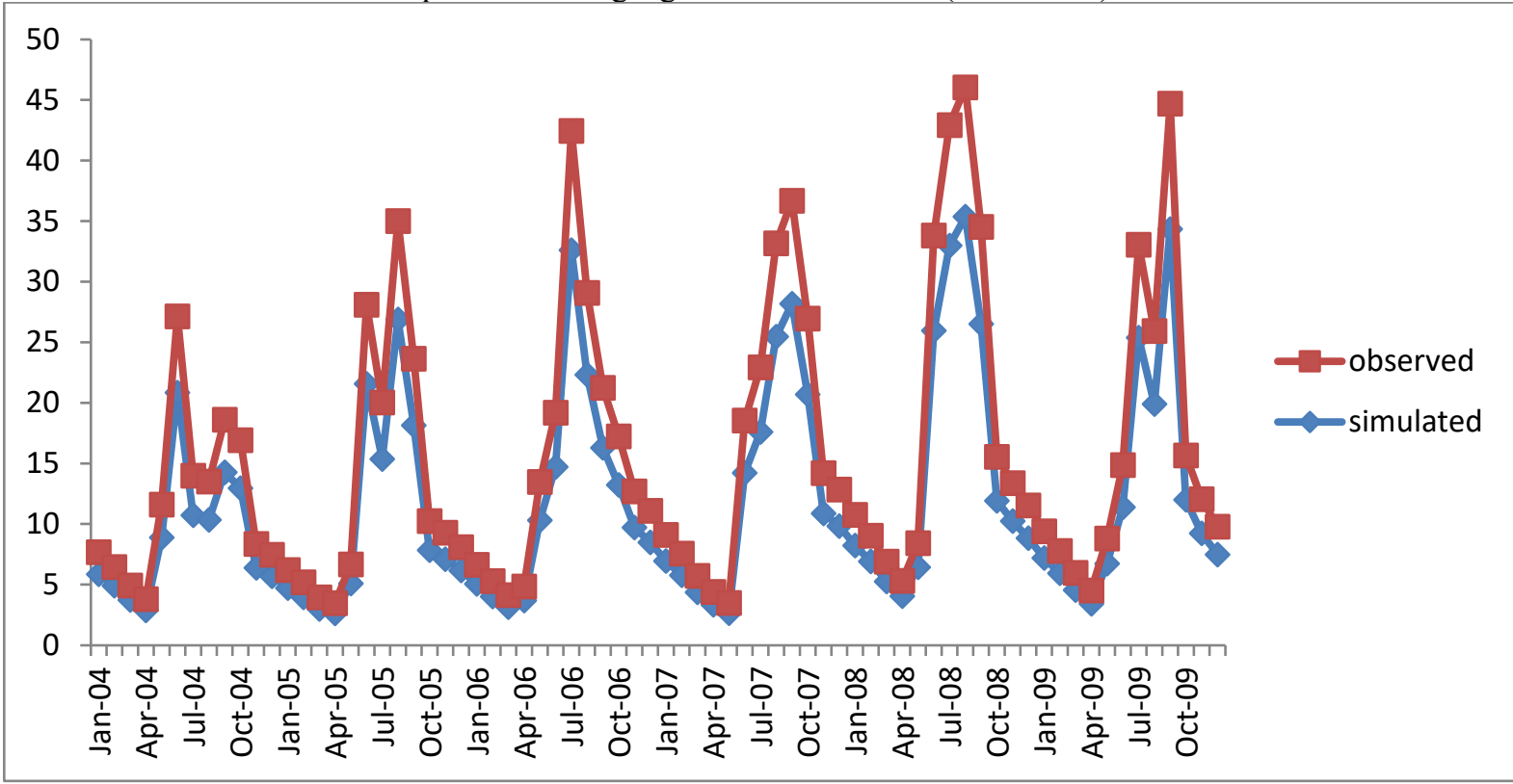

Figure 3.5.Validation result of Monthly simulated and measured flow at Aleltu near Nedjo gauging station is located. 


\subsubsection{Monthly, seasonal, annual stream flow changes}

The flow is simulated using SWAT Model for the future periods from 2025-2049, 2050-2074 and 2075-2099 for both RCP4.5 and RCP8.5 scenarios. The figure 4.6 shows the average monthly flow calculation for each condition, percentage Change from simulated flow under both scenarios and the three future periods. Seasonal changes occur when, mean seasonal flow showed decrease for all seasons except winter in the (2075-2099) period for RCP 8.5 as shown in Figure 4.6, which was consistent with the precipitations trend of the period. In RCP4.5 the average change in flow from all period shows decreasing. In spring season, a small rainy season in the basin, flow is expected to increase by an average of $0.45 \%$ under RCP4.5 and decrease by $4.21 \%$ under RCP8.5 scenarios. Similarly, as figure above shows under RCP 4.5and RCP8.5 scenario simulated discharge project a decreasing of flow but among the all decreasing months September is a stressful month and water withdrawal need to be considered seriously. The projected decrease in mean monthly flow is obtained compared to the baseline period. As shown in the figure 3.6 compared to other months of seasons the distribution of stream flow seems mostly decreasing highly starting from June and it becomes large at the September.

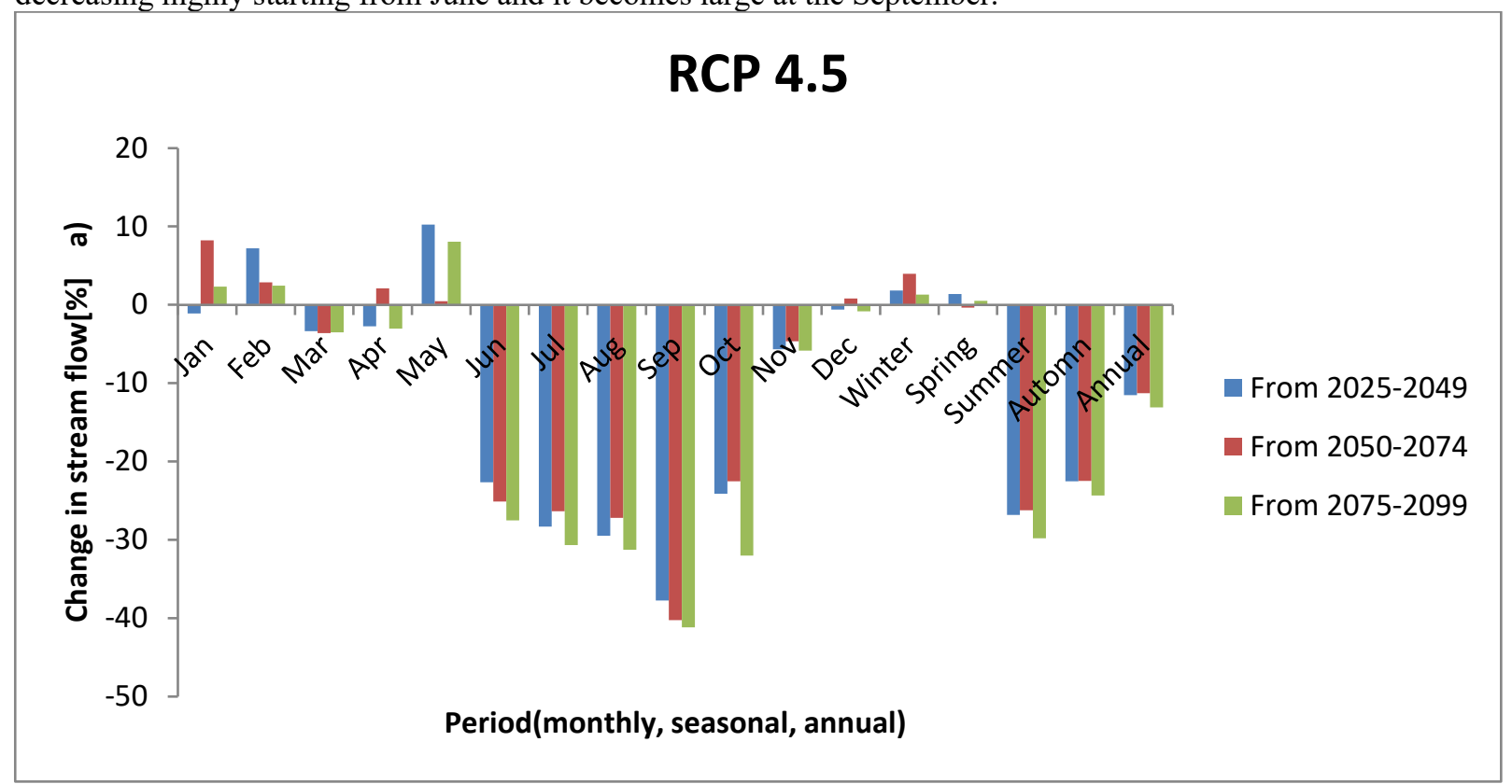

\section{RCP8.5}

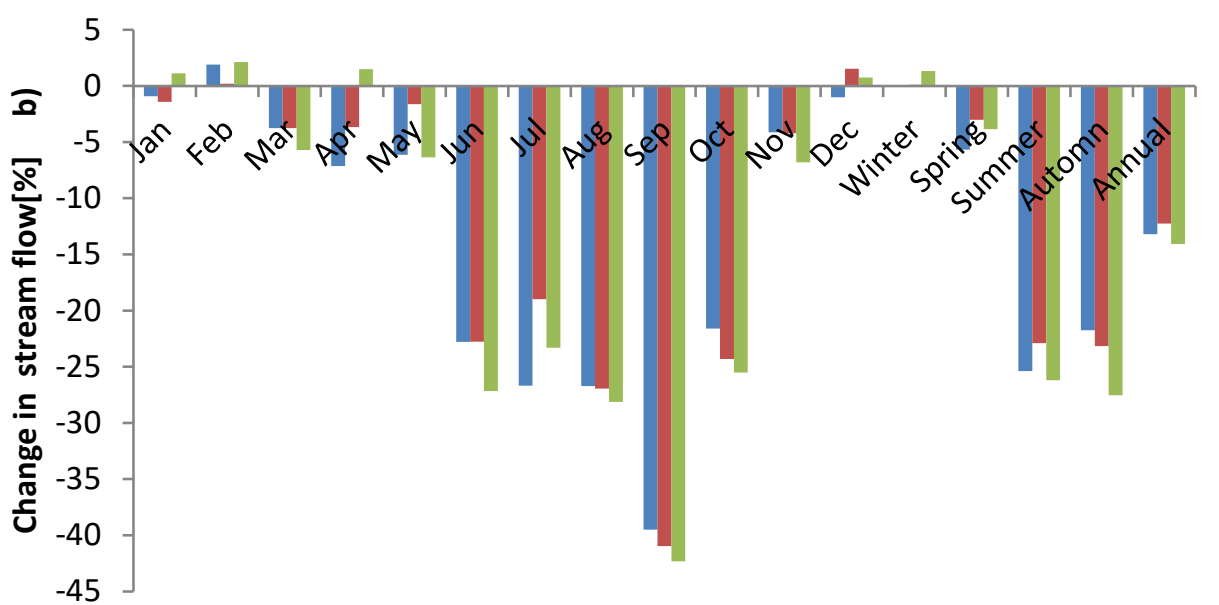

From 2025-2049

- From 2050-2074

From 2075-2099

Period(monthly, seasonal, annual)

Figure 3.6: Monthly mean flow changes (a) under RCP4.5 and (b) under RCP8.5 for the three future periods. 